\title{
The Cultivation of Autonomous Learning Ability in College English Teaching Reform
}

\author{
Li Ying ${ }^{1,}$ Tian Lijuan ${ }^{2}$ and Wang Ying ${ }^{3}$ Tangshan College \\ ${ }^{1,3}$ Foreign Languages Department, ${ }^{2}$ Department of Economy and Management \\ Tangshan College, tsc \\ Tangshan, China \\ ${ }^{1}$ liying7311@yahoo.com.cn, ${ }^{2}$ gaolangyu2002@163.com, ${ }^{3}$ angle1000@sina.com
}

\begin{abstract}
Autonomous learning ability has long been a hot issue, which is also one of the objectives of college English teaching (CET) reform being carried out in most Chinese universities and colleges nowadays. The paper puts forward a few personal views on how to cultivate students' autonomous learning ability.
\end{abstract}

\section{Keywords- autonomous learning; CET}

With more emphasis laid on "taking learner as the centre”, the cultivation of students' autonomous learning ability has become one of the objectives of college English teaching (CET), which is stipulated clearly in "English Course Requirements for Non - English Majors” issued by Ministry of Education in 2007. Therefore, the primary purpose of CET reform should be focused on students' learning, that is, the cultivation of their autonomous learning ability to make them live up to the course requirements and of their sustainable learning ability to be lifelong learners.

\section{A BRIEF INTRODUCTION TO CET REFORM}

In 2004, Ministry of Education approved reform experimentation in 180 universities and colleges, which pushed forward the CET reform, leading the CET towards the development of "individualization, collaboration, modularization and hypertext” [1]. Since 2007, the CET reform has been launched on a large scale in most universities and colleges in China. In most cases, new concept of teaching management, together with advanced modern computer technology and abundant network resource plays a vital role, which guarantees that students can learn college English via Campus Network independently.

In the case of the author's college, the CET reform is implemented in the following ways. Firstly, graded teaching has been carried on to satisfy the needs of individualized teaching and promote teaching effect. Secondly, computerbased teaching and classroom teaching are integrated. A comprehensive, three-dimensional English teaching and learning environment has been created, which includes English materials of print, CD, network version. Besides, curriculum has been diversified to include both basic English course such as listening, reading, speaking, writing and expanding courses such as advanced English, American culture, business English, etc.

\section{THE CONCEPT OF AUTONOMOUS LEARNING}

The concept of autonomous learning was introduced to foreign language teaching in 1980s, but there is no agreedupon definition of it till now. Henri Holec defines autonomous learning as "the ability to take charge of one's own leaning” [2]. According to David Little, learner autonomy is "essentially a matter of the learner's psychological relation to the process and content of learning... a capacity for detachment, critical reflection, decision-making, and independent action" [3]. Though differing in their definition, most scholars agree that learner autonomy means the learner's ability to take control of his/her own learning.

Generally speaking, autonomous learning is a kind of modern learning theory based on humanistic psychology. It is also a kind of learning model in which the learner plans and sets his/her own learning objective independently or under the teacher's help, implements and fulfills the plan individually or collaboratively with others, then evaluates his/her own learning outcome, and achieves the learning objective eventually.

\section{THE CULTIVATION OF AUTONOMOUS LEARNING ABILITY}

\section{A. Changing the teachers' role}

The necessity for teaching students how to become independent and autonomous learners has brought new perspectives to the teaching profession and changed traditional ideas about language teacher's roles. "The teacher can help, advice and teach; but only the learner can learn” [4]. To be active learners, students must take an active part in learning practices and cognitive activities to bring out their full potentials. Teachers must change their roles to be organizers, managers, facilitators and consultants of learning, leaving the initiative to the students, giving them enough time and space to explore, discuss and solve the problems independently. The new perspectives focus on what teachers can do to facilitate their students' language learning. New roles for teachers include helpers, facilitators, advisors and guides [5].

In preparing students to be autonomous learners, the teachers should firstly know their beliefs and needs. Learners' beliefs have the potential to influence both learners' experiences and actions as language learners. Erroneous beliefs about language learning may lead to the 
utilization of less effective strategies and hence impede their language learning process. Only by knowing the learners' beliefs, can the teachers get a preliminary picture about the students and consequently prepare them for the autonomous learning. Each student has his/her own learning goal, learning pace, strategy preference and way of selfassessment. As it is the students who will be using the language they are learning, it's reasonable to assume that they may know what they should learn. Through investigating learners' needs, the teachers can get a clear picture of their teaching as to what materials they will provide, what methods they will use and how to exercise the teaching process.

When students are entering autonomous study, the teachers should prepare learners for their new role by developing learners' self-awareness as language learners. At this time, the teacher should assume the role of a psychologist, a good communicator and instructor. As a psychologist, the teacher should fulfill the utmost important task of enhancing students' motivation, cognitive competence and metacognitive competence. The teacher should try to establish students' awareness that language learning is a process in which they should be active participants and reflective thinkers. As a good communicator, the teacher should try to know clearly of the students' beliefs, needs and attitudes towards this mode of learning by communicating with them. Besides, the teacher should make the students aware that they should take more responsibilities in learning at college compared with that at high school. As a good instructor, the teacher should guide students of different levels to set proper learning goals tailored to students' individual circumstances, help and supervise them to realize their fixed objectives. Moreover, the teacher should also carry out instructions in operating the computers and guide students to locate and use information through computers and the internet.

B. Providing an autonomous learning environment by using multi-media and network information technology

Learning depends to a large extent on the individual learner and the environment that interact with the learner. In order to achieve the ideal autonomous learning results, a good personalized learning environment must be provided. Teachers, resources and media compose the autonomous learning environment to facilitate the students, in which students can "travel" around the world by chatting with people from different races and cultures, reading newspapers and magazines and watching TV programmes worldwide. Applying multimedia and internet to English teaching could create more and more authentic language environment for the learners, which enables them to communicate in English in real-life situations. Besides, the autonomous learning centers can also be used in network-based language teaching, which can not only alleviate the scarcity of teaching faculty in some colleges, but also train the students' practical abilities in listening, reading, speaking, writing and translating. In the autonomous learning centers, students have free access to the campus network to learn English independently. If they have questions, they can enter the chat room of the online class to have a discussion with classmates or teachers. Online discussion benefits both the extroverted and introverted students. The latter feel more comfortable to air their viewpoints via the computer.

In such a learning environment, students need teachers' guide and help in particular. It's the teachers' job to help students choose learning materials according to their own level and needs, and choose language activities according to their own interests. Teachers can provide on-line auxiliary teaching, offering guide to different levels of students via homepage. At the same time, students can pose questions, submit their assignments to the teachers by e-mail, and teachers can interact with students by giving them timely feedback through e-mail. Teachers can also encourage students to combine autonomous learning with group learning and share their learning experience, thus improving their language proficiency on the whole.

C. Integrating e-learning and face-to-face instruction

In the context of online learning environment, teachers' role in classroom instruction should be strengthened rather than be weakened. Internet is a bridge through which teachers and students can communicate with each other, while classroom is a place where students can present themselves. Students' online autonomous learning can't be carried out as they like, and there must be objectives, tasks, and inspections. Online learning should be the expansion and supplement of classroom learning, which needs teachers' guide and help. After students' finishing their online course or CD course, teachers should offer them timely face-to-face instruction. In the classroom, students can present their achievements in autonomous learning, after which teachers can find out the imperfection and disabuse students' confusion. Therefore, teachers must manage the teaching process quantitatively and carry out diagnostic and targeted teaching to increase efficiency. Only in this way, can the teachers get the first-hand feedback of learning information and guide students to make timely adjustment to their autonomous learning. Through constant and timely adjustment, good learning outcome will be attained eventually.

\section{Applying multi evaluation}

Teaching evaluation plays an important role in encouraging, guiding and monitoring the quality of teaching, which should be changed with the change of curriculum and teaching model. For a long time, it is the teachers who have been evaluating the students, and summative assessment, that is, examination has been the major way used to evaluate students' performance in English study. This single way of evaluation puts more emphasis on the learning results and neglects the learning process, so it no longer adapts to the CET reform, especially the development of students' autonomous learning ability. Diversifying evaluation system can evaluate students' potential and academic achievement comprehensively, which offers information to improve teaching and promote autonomous learning ability.

In the multi evaluation system, both teachers and students themselves can make the assessment concerning students' study, with both formative and summative assessment, both qualitative and quantitative assessment being used. It can put an end to the phenomenon of cramming for exams rather 
than working hard regularly, thus making students know that "the evaluation is not for the proof, but to improve" [6]. Evaluation is not for screening and rating, but to promote students' growth and development; it's not for telling students their learning outcome, but to motivate them to learn better. Multi evaluation can arouse students' learning interests with abundant classroom activities and improve students' autonomous learning ability. In a survey conducted by GaoYan [7] among 288 students in Shandong University, $91 \%$ of the students believed that multi evaluation contributed to the improvement of their autonomous learning ability.

With the development of CET reform, more emphasis has been laid on the "student-centered" teaching model. How to cultivate students to be autonomy learners and help them improve their comprehensive English level through autonomous learning is the urgent thing in CET, so our teaching objectives must be focused on the cultivation of students' autonomous learning ability. As teachers, we must change our traditional doctrines and refocus our roles in teaching, reform the organization of class and the way we normally teach, and pay due attention to the students. We should stay aware of the students' needs and individual features, provide them with autonomous learning environment, and try to realize learner autonomy to the maximum. Ways to cultivate students' autonomous learning ability should be used in combination with other teaching methods to improve CET, and bring up high quality persons to society in the long run.

\section{REFERENCES}

[1] $\mathrm{Hu}$ Zhuanglin, On the Individualization, Collaboration, Modularization and Hypertext in College English Teaching. Beijing: Foreign Language Teaching and Research, 2004, pp. 345-350

[2] H. Holec, Autonomy and Foreign Language Learning. Oxford: Pergamon, 1981, p.68.

[3] D. Little, "Developing Learner Autonomy in the Foreign Language Classroom: A Social-interactive View of Learning and Three Fundamental Pedagogical Principles.” Revista Canaria de Estudios Ingleses, vol. 38, 1999, pp. 77-88.

[4] K.Johnson, \& K. Morrow, Communication in the Classroom. England: Longman Group Ltd. 1981

[5] J.M. O’Malley, \& J.M. Charnot, Learning Steategies in Second Language Acquisition. Cambridge: CambridgeUniversity Press, 1990

[6] D. L. Stufflebeam, \& A. J. Shinkfield, Systematic Evaluation. Boston: Kluwer- Nijhoff. 1985.

[7] Gao Yan, “Multi Evaluation: Promoting Students' All-round Development”. Link \& Think, Vol.1, 2008, pp.27-30 